\title{
Исследование сорбции аммиака из газовоздушной среды модифицированными ионообменными волокнами
}

\author{
(C) 2021 Перегудов Ю.С., Плотникова С.Е.. Горбунова Е.М, \\ Тимкова А.В., Ким К.Б., Нифталиев С.И.
}

Воронежский государственный университет инженерных технологий, Воронеж

Поступила в редакцию 5.03.2021 г.

DOI: $10.17308 /$ sorpchrom.2021.21/3468

Очистка технологических газов от аммиака является актуальной проблемой в химической промышленности. Целью работы было изучение сорбции аммиака из газовоздушной среды модифицированными волокнистыми сорбентами. В качестве сорбента аммиака использовали карбоксильное волокно ВИОН КН-1 в медной, никелевой и цинковой формах. Исследование поглощения аммиака проводили на воздушно-сухих и влагонасыщеных образцах волокнистого сорбента. Для изучения сорбции в эксикаторах создавали атмосферы с объемной концентрацией аммиака от 10 до 300 мг/м ${ }^{3}$. Предельно допустимая концентрация содержания аммиака в воздухе рабочей зоны составляет $20 \mathrm{мг} / \mathrm{M}^{3}$. Модифицированные волокнистые сорбенты после сорбции аммиака приобретали цвета, характерные для аминокомплексов. Волокно с поглощенным аммиаком обрабатывали раствором соляной кислоты с концентрацией 0.1 моль/дм³ в статических условиях при температуре 293 К в течение 90 минут. Концентрацию ионов аммония определяли на иономере И-130 с ионоселективным электродом. Фотометрический метод применяли для определения концентрации ионов металлов в растворах после десорбции. Установлено, что медная форма поглощает наибольшее количество аммиака. При низких значениях давления газа наблюдается резкое поглощение аммиака модифицированным волокном. Не модифицированное волокно обладает меньшей сорбционной способностью, что объясняется различным механизмом сорбции молекул аммиака на протонированной и ионных формах волокнистого сорбента. Для количественного описания равновесного процесса сорбции аммиака модифицированными волокнами были использованы уравнения Ленгмюра и Фрейндлиха. Коэффициенты корреляции для уравнения Ленгмюра близки к единице. При высоких давлениях происходит полное насыщение сорбента и повышение давления уже не влияет на абсорбцию газа. Полученные результаты по сорбции аммиака согласуются с квантово-механическими расчетами в программном модуле Нуреr Chem об образовании на карбоксильном волокне, содержащем как медь, так и никель, комплексов, в состав которых входят от 1 до 3 молекул аммиака. Кинетические зависимости сорбции аммиака на образцах медной и никелевой форм волокна ВИОН КН-1 были получены при концентрации аммиака в газовой фазе $10 \mathrm{Mг} / \mathrm{M}^{3}$. Показано, что более высокой скоростью сорбции характеризуется медная форма волокнистого сорбента. Насыщение модифицированных карбоксильных волокон парами воды ухудшает их сорбционные свойства на 8-10\%.

Ключевые слова: сорбция, аммиачные комплексы, модифицированные карбоксильные волокна.

\section{Введение}

В химической промышленности аммиак широко используется при производстве минеральных удобрений, азотной кислоты и относится к одним из распространенных загрязнителей воздуха. Актуальными являются вопросы по очистке промышленных выбросов газов в атмосферу и санитарно-химическому контролю воздуха рабочей зоны. 
Усиление требований к охране окружающей среды и безопасности жизнедеятельности человека предполагает создание экспрессных способов определения аммиака в газовоздушных средах, характеризующихся низкими пределами обнаружения, селективностью, простотой аппаратурного решения.

\section{Теоретическая часть}

Литературный обзор показывает, что созданию сорбентов аммиака, исследованию их свойств, а также методам физического и химического воздействия на структуру сорбирующих материалов уделяется большое внимание. Изучено влияние ультразвука на насыщение композитов солями переходных металлов и сорбцию аммиака полученными сорбентами [1]. Наиболее оптимальными условиями насыщения сульфатом меди $\mathrm{Al}_{2} \mathrm{O}_{3}$ являются мощность 60 Вт и время 100 сек. Сорбционная способность по аммиаку композита $\mathrm{Al}_{2} \mathrm{O}_{3}-\mathrm{CuSO}_{4}$ примерно в 10 раз эффективнее, чем без ультразвука.

Исследована адсорбция аммиака композитами, полученными путем модифицирования анодного пористого оксида алюминия солями серебра, никеля, меди и кобальта [2]. Кроме неорганических солей для модифицирования также применяются углеродные нанотрубки (УНТ), выращенные на каталитических затравках в каналах пор и на поверхности наноструктурированного $\mathrm{Al}_{2} \mathrm{O}_{3}$. Изучение кинетики сорбции аммиака позволило определить наиболее эффективную систему: $\mathrm{Al}_{2} \mathrm{O}_{3}-\mathrm{CuSO}_{4}>\mathrm{Al}_{2} \mathrm{O}_{3}-\mathrm{NiSO}_{4}>\mathrm{Al}_{2} \mathrm{O}_{3}-$ $\mathrm{AgNO}_{3}>\mathrm{Al}_{2} \mathrm{O}_{3}-\mathrm{CoSO}_{4}$. Понижение адсорбционной способности в этом ряду объясняется уменьшением комплексообразующих свойств ионов металлов по отношению к $\mathrm{NH}_{3}$. В работе показано, что адсорбционные свойства у УНТ в 2.8-3 раза лучше, чем у угля АГ-3.

Авторы исследования [3] изучали сорбционные свойства силикагелей по аммиаку и установили, что размер пор силикагелей влияет на их поглотительные свойства. Показано, что термически модифицированный мелкопористый силикагель обладает лучшими сорбционными свойствами.

Проведена химическая обработка термически активированных сорбентов в растворе сульфата меди [4]. Основываясь на изучении десорбционных процессов методом ИК-спектроскопии, представлен механизм сорбции аммиака, который определяется видами взаимодействия в системе сорбент - сорбат. Наибольшая сорбционная способность мелкопористого силикагеля обусловлена физической адсорбцией и образованием водородных связей молекул аммиака со структурными группами на поверхности силикагеля (силанольными и вицинальными). У крупнопористого силикагеля преобладает химическая составляющая адсорбции, связанная с образованием амминокомплексов меди.

Давно в качестве адсорбентов газов используются активированный уголь и композиты на его основе [5-7]. Предложен сорбент «Busofit», представляющий собой активированное углеродное волокно, насыщенное хлоридами или гидридами металлов для систем хранения аммиака, метана и водорода [5,6]. Модифицирование солями и гидридами металлов углеродного волокна увеличивает как физическую, так и химическую сорбцию газов.

Динамическим методом изучена зависимость равновесной адсорбционной емкости активного угля АГ-3 по парам аммиака от парциального давления при 0.115 кПа и температуре 288-323К при сорбции аммиака из влажных газов [7]. Объем микропор образцов угля равен $0.31 \pm$ $0.02 \mathrm{~cm}^{3} / г$. Приведено уравнение для расчета сорбционной емкости угля в изученном интервале изменения параметров адсорбции. Теплота адсорбции, равная 3739 кДж/моль, больше теплоты конденсации паров $\mathrm{NH}_{3}$ примерно на 20 кДж/моль, что характерно для физической адсорб- 
ции. При регенерации поглотившего аммиак угля, отмечена стабильность адсорбционной емкости.

Также представляет интерес ряд исследований, посвященных сорбции газов сорбентами, полученными путем модифицирования различных матриц неорганическими солями [8-11]. Авторы работы [8] изучали сорбцию аммиака на новых композитных сорбентах на основе $\gamma$ $\mathrm{Al}_{2} \mathrm{O}_{3}$ и вермикулита. Установлено, что модифицирование этой матрицы солью $\mathrm{CaCl}_{2}$ увеличивает сорбцию аммиака за счет образования комплексов $\mathrm{CaCl}_{2} \cdot \mathrm{nNH}_{3}$.

Предложена концепция целенаправленного синтеза двухкомпонентных адсорбентов «соль в пористой матрице», предназначенных для осушки газов и поддержания постоянной влажности [9].

Новые композитные материалы на основе пористых вермикулита, $\gamma-\mathrm{Al}_{2} \mathrm{O}_{3}$ и углеродного сибунита, пропитанные $\mathrm{BaCl}_{2}$, показали себя как эффективные сорбенты аммиака [10]. Модифицирование матрицхозяев солью увеличивает поглощение аммиака из-за химического взаимодействия аммиака с хлоридом бария.

Новый композиционный сорбент получен обработкой войлока АCF водным раствором $\mathrm{CaCl}_{2}$ [11]. Изостеры сорбции аммиака измерены при $\mathrm{t}=20-90^{\circ} \mathrm{C}$ и $\mathrm{P}=0.1-9.0$ бар. Метод заключался в нагреве сорбента в замкнутом объеме адсорбера с регистрацией давления равновесия аммиака в зависимости от температуры. Поглощение находилось в диапазоне 5.7-36.9 мас.\%.

В сорбционных технологиях также используются и ионообменные волокна с различными функциональными группами для очистки воздуха от примесей газов кислотного и основного характеров $[12,13]$. Большой интерес представляют волокнистые хемосорбенты ВИОН, которые были синтезированы под руководством профессора Зверева М.П. В отличие от рассмотренных выше типов сорбентов аммиака ионообменные волокна обладают рядом преимуществ. При применении волокон в качестве сорбентов реализуются не только электровалентные взаимодействия, но и координационные, водородные связи, различные типы межмолекулярного притяжения. Для ионообменных волокон характерны развитая поверхность и малое сопротивление фильтрующего слоя. Это позволяет их использовать в качестве фильтрующего материала в различных формах (волокно, мембраны, нетканое полотно) и практически в любых конструкциях оборудования по очистке воздуха. В отличие от зернистых аналогов, волокнистые материалы обладают более высокой скоростью сорбции загрязняющих компонентов из водных и газовоздушных систем. При этом сорбционное равновесие устанавливается очень быстро.

Цель работы - получение новых модифицированных волокнистых сорбентов для очистки газовоздушных сред от аммиака и исследование их сорбционных характеристик.

\section{Экспериментальная часть}

В качестве сорбента аммиака использовали ионообменное волокно ВИОН КН-1 с функциональными группами $\mathrm{COOH}$ (рис.1). Его получали омылением

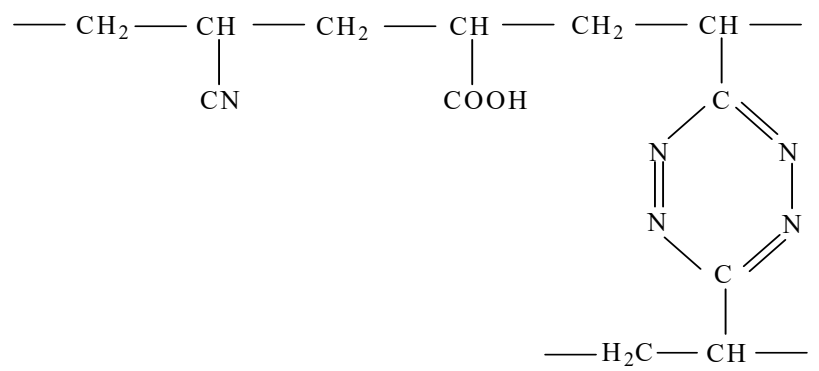

Рис.1. Структура ионообменного волокна ВИОН КН-1 в водородной форме Fig. 1. Structure of the ion-exchange fiber VION KN-1 in the hydrogen form 
$\mathrm{a}$

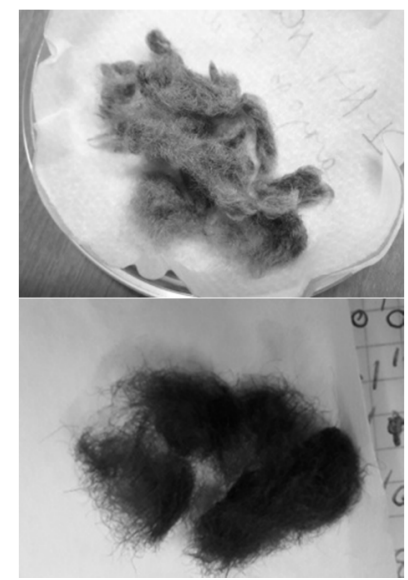

6

д

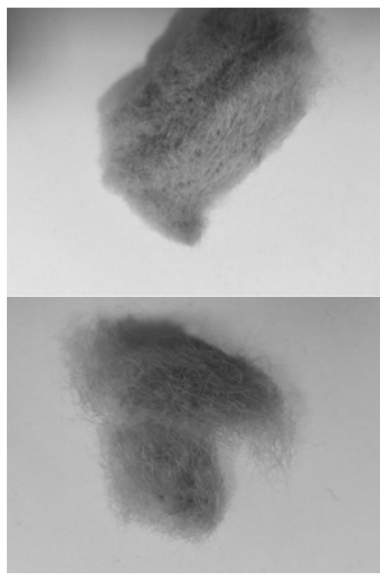

B

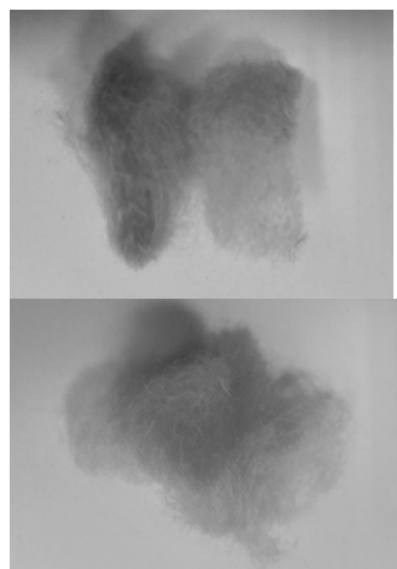

Рис. 2. Фотографии образцов волокна ВИОН КН-1 в ионных формах: (а - медная (зеленый цвет), б - никелевая (коричневый цвет), в - цинковая) и в комплексных формах, насыщенных аммиаком (г- $\mathrm{Cu}^{2+}$ (темно-синий цвет), д $-\mathrm{Ni}^{2+}$ (серый цвет), $\mathrm{e}-\mathrm{Zn}^{2+}$ ).

Цинковое волокно имеет окрашивание, характерное для исходной водородной формы (розовый цвет).

Fig. 2. Photographs of VION KN-1 fibre samples in ionic forms $(\mathrm{a}$ - copper, $\mathrm{b}$ - nickel, $\mathrm{c}-$ zinc $)$ and in complex forms saturated with ammonia $\left(\mathrm{d}-\mathrm{Cu}^{2+}, \mathrm{e}-\mathrm{Ni}^{2+}, \mathrm{f}-\mathrm{Zn}^{2+}\right)$

сшитого гидразингидратом полиакрилонитрильного волокна (нитрон). Набухание ВИОН КН-1 в воде составляет 3-6 мас.\% .

Для ионообменных волокон характерна развитая поверхность, что способствует более легкому доступу реагентов к активным группам. Волокно кондиционировали по стандартным методикам. Затем его переводили в медную, никелевую и цинковую формы динамическим мето- дом, пропусканием раствора нитрата соответствующего металла с концентрацией 0.1 моль/дм ${ }^{3}$ В результате, образцы волокна меняли цвет (рис. 2 а-в). Цинковое волокно имеет окрашивание, характерное для исходной водородной формы. Известно, что в растворе катионы данных металлов в свободном виде не существуют, они образуют аквакомплексы, например, $\left[\mathrm{Cu}\left(\mathrm{H}_{2} \mathrm{O}\right)_{4}\right]^{2+}$.

Таблица 1. Массовая доля кинетически неравноценной воды в модифицированных волокнах ВИОН КН-1

Table 1. Mass fraction of kinetically unequal water in modified VION KN-1 fibres

\begin{tabular}{|c|c|c|c|c|}
\hline $\begin{array}{c}\text { № } \\
\text { П/П }\end{array}$ & $\begin{array}{c}\text { Модифицирован- } \\
\text { ная форма во- } \\
\text { локна ВИОН КН- } \\
1\end{array}$ & $\begin{array}{c}\text { Массовая доля воды, } \\
\text { \% (молекулы воды, } \\
\text { образующие связи } \\
\text { по типу диполь-ди- } \\
\text { польного взаимодей- } \\
\text { ствия, область даль- } \\
\text { ней гидратации) }\end{array}$ & $\begin{array}{c}\text { Массовая доля } \\
\text { воды, \% } \\
\text { (молекулы } \\
\text { воды, образую- } \\
\text { щие ассоциаты } \\
\text { и находящие } \\
\text { вблизи функци- } \\
\text { ональных } \\
\text { групп волокна } \\
\text { и проти- } \\
\text { воионов, об- } \\
\text { ласть средней } \\
\text { гидратации) }\end{array}$ & $\begin{array}{c}\text { Массовая доля } \\
\text { воды, \% (моле- } \\
\text { кулы воды, взаи- } \\
\text { модействующие с } \\
\text { карбоксильными } \\
\text { группами волокна } \\
\text { и противоионами } \\
\text { по ион-диполь- } \\
\text { ному типу, об- } \\
\text { ласть ближней } \\
\text { гидратации) }\end{array}$ \\
\hline 1 & $\mathrm{Cu}^{2+}$ & 20 & 39 & 41 \\
\hline 2 & $\mathrm{Ni}^{2+}$ & 26 & 33 & 41 \\
\hline 3 & $\mathrm{Zn}^{2+}$ & 23 & 43 & 34 \\
\hline
\end{tabular}


Таблица 2. Расчетные данные по содержанию аммиака в растворе и газовой фазе Table 2. Calculated data on the content of ammonia in the solution and gas phase

\begin{tabular}{|c|c|c|c|}
\hline $\begin{array}{c}\text { № } \\
\text { П/ח }\end{array}$ & $\begin{array}{c}\text { Концентрация в газовой } \\
\text { фазе, мг } / \mathrm{M}^{3}\end{array}$ & Давление, кПа & $\begin{array}{c}\text { Массовая доля } \mathrm{NH}_{3} \\
\text { в растворе, } \%\end{array}$ \\
\hline 1 & 10.00 & 1.43 & 1.46 \\
\hline 2 & 13.62 & 1.95 & 2.23 \\
\hline 3 & 15.70 & 2.25 & 2.64 \\
\hline 4 & 20.20 & 2.90 & 3.46 \\
\hline 5 & 35.93 & 5.15 & 5.84 \\
\hline 6 & 76.09 & 10.90 & 10.29 \\
\hline 7 & 139.17 & 19.94 & 15.39 \\
\hline 8 & 295.74 & 42.38 & 24.43 \\
\hline
\end{tabular}

Ионообменные разделения основаны на селективном распределении компонентов между фазами. Межфазный перенос растворителя является одним из факторов, определяющих положение ионообменного равновесия на набухающих волокнистых сорбентах. Методом дифференциальной сканирующей калориметрии и изопиестическим методом была проведена оценка состояния воды в модифицированных формах волокна ВИОН КН-1 солями металлов $\left(\mathrm{Cu}^{2+}, \mathrm{Ni}^{2+}, \mathrm{Zn}^{2+}\right)$ [14]. Показано, что природа и наличие ионов металлов влияет на количество сорбированной волокном воды. Установлено разное количество кинетически неравноценной воды в ионных формах волокна (табл. 1).

Видно, что доля прочно- и среднесвязанных молекул воды для медной формы больше, чем для никелевой и цинковой. Это различие должно влиять на сорбцию аммиака модифицированными волокнами. Ионообменные волокна можно использовать для сорбции аммиака в газах, имеющих высокую влажность. Волокно ВИОН КН-1 сорбирует не только газообразный аммиак, но и его туман.

Исследование поглощения аммиака проводили на воздушно-сухих образцах. Для определения влияния воды на сорбцию аммиака готовили образцы, насыщенные парами воды. Для этого навеску волокна ВИОН КН-1 в медной форме массой 0.15 г выдерживали при 293 К над насыщенным раствором $\mathrm{K}_{2} \mathrm{Cr}_{2} \mathrm{O}_{7}$ с упру- гостью водяного пара 0.980 до установления равновесия. Критерием достижения равновесия служило постоянство массы образца, количество поглощенной воды определяли гравиметрическим методом.

Для изучения сорбции в эксикаторах создавали атмосферы с объемной концентрацией аммиака от 10 до 300 мг/м ${ }^{3}$. Предельно допустимая концентрация (ПДК) содержания аммиака в воздухе рабочей зоны составляет $20 \mathrm{Mг} / \mathrm{M}^{3}$. Литературные данные зависимости давления в газовой фазе от массовой доли аммиака в растворе [15] аппроксимировали квадратным уравнением с достоверностью 0.999 (рис.3).

Давление аммиака в газовой фазе рассчитывали по уравнению МенделееваКлайперона для заданных объемных концентраций. Используя уравнение аппроксимации, вычисляли массовые доли аммиака в водных растворах, помещаемых в эксикаторы (табл. 2).

Для приготовления рабочих растворов использовали аммиак с массовой долей $24.43 \%$. В эксикаторы с растворами аммиака, помещали навески волокна массой 0.15 г и выдерживали сутки при температуре 293 К. После проведения процесса сорбции аммиака на образцах солевых форм, волокна приобретали цвета, характерные для аминокомплексов (рис. 2 г-е), изменение окрашивания можно считать своеобразным аналитическим сигналом.

При поглощении аммиака солевой формой волокна протекают реакции: $\left[\mathrm{Cu}\left(\mathrm{H}_{2} \mathrm{O}\right)_{4}\right]^{2+}+4 \mathrm{NH}_{3}=\left[\mathrm{Cu}\left(\mathrm{NH}_{3}\right)_{4}\right]^{2+}+4 \mathrm{H}_{2} \mathrm{O}$; 


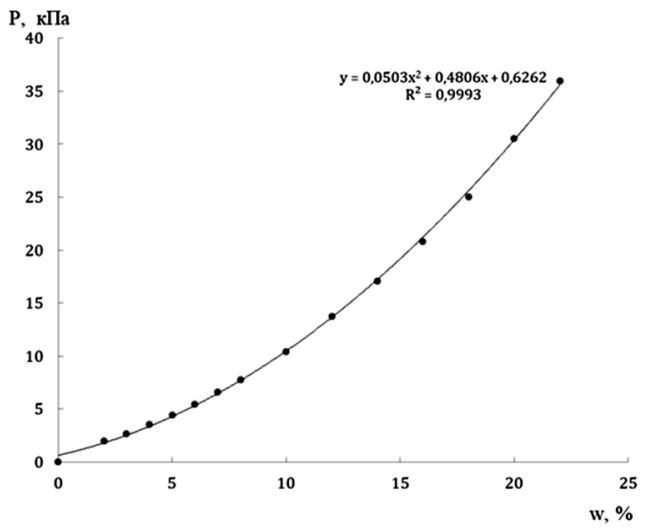

Рис. 3. Зависимость давления $\mathrm{NH}_{3}$ в газовой фазе от массовой доли аммиака в растворе при $293 \mathrm{~K}$

Fig. 3. Dependence of $\mathrm{NH}_{3}$ pressure in the gas phase on the mass fraction of ammonia in solution at $293 \mathrm{~K}$

$\left[\mathrm{Zn}\left(\mathrm{H}_{2} \mathrm{O}\right)_{4}\right]^{2+}+4 \mathrm{NH}_{3}=\left[\mathrm{Zn}\left(\mathrm{NH}_{3}\right)_{4}\right]^{2+}+4 \mathrm{H}_{2} \mathrm{O}$; $\left[\mathrm{Ni}\left(\mathrm{H}_{2} \mathrm{O}\right)_{6}\right]^{2+}+6 \mathrm{NH}_{3}=\left[\mathrm{Ni}\left(\mathrm{NH}_{3}\right)_{6}\right]^{2+}+6 \mathrm{H}_{2} \mathrm{O}$.

Полученные аминокомплексы металлов различаются по строению и константам нестойкости, которые приведены в таблице 3 [15].

Затем волокно с поглощенным аммиаком обрабатывали раствором соляной кислоты с концентрацией 0.1 моль/дм ${ }^{3}$ в статических условиях при температуре 293 К в течение 90 минут при перемешивании. При этом волокно принимало исходный цвет, что свидетельствовало о разрушении комплексов и переходе в раствор катионов комплексообразователя и лигандов. В кислой среде аммиак переходит в катион аммония, который уже не содержит неподеленных пар электронов и поэтому не может выполнять функции лиганда:

$$
\left[\mathrm{Cu}\left(\mathrm{NH}_{3}\right)_{4}\right]^{2+}+4 \mathrm{H}^{+}=\mathrm{Cu}^{2+}+4 \mathrm{NH}_{4}{ }^{+}
$$

Далее раствор фильтровали для удаления частичек волокна и определяли концентрацию ионов аммония в растворе на иономере И-130 с ионоселективным элек-

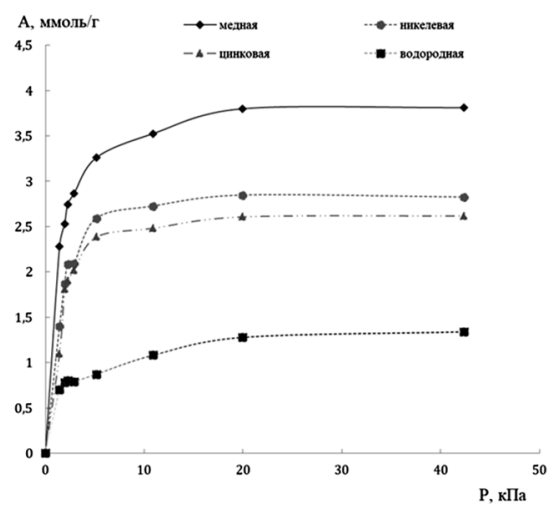

Рис. 4. Изотермы сорбции аммиака солевыми формами ВИОН КН-1 от давления

Fig. 4. Isotherms of ammonia sorption by salt forms of VION KN-1 from pressure

тродом по градуировочному графику (зависимость напряжения от логарифма молярной концентрации). Количество сорбированного вещества (моль/г) рассчитывали по формуле:

$$
A=\frac{C \cdot V}{m},
$$

где $\mathrm{m}$ - масса навески волокна, г; $\mathrm{V}$ - объем раствора соляной кислоты, дм$^{3} ; \mathrm{C}-$ концентрация ионов аммония, моль/дм ${ }^{3}$.

Для определения концентрации ионов меди, цинка и никеля в растворах после десорбции использовали фотометрический метод [16].

\section{Обсуждение результатов}

На рис. 4 представлены зависимости сорбции аммиака ионными формами волокна от давления.

Видно, что при низких значениях давления газа наблюдается резкое поглощение аммиака волокном. Начальный участок изотерм будет соответствовать заполнению наиболее активных доступных

Таблица 3. Константы нестойкости изучаемых металлов

Table 3. Instability constants of the studied metals

\begin{tabular}{|c|c|c|c|}
\hline № & Комплексный ион & Пространственная конфигурация & К $_{\text {нест }}$ \\
\hline 1 & {$\left[\mathrm{Cu}\left(\mathrm{NH}_{3}\right)_{4}\right]^{2+}$} & квадратная & $2 \cdot 10^{-13}$ \\
\hline 2 & {$\left[\mathrm{Zn}\left(\mathrm{NH}_{3}\right)_{4}\right]^{2+}$} & квадратная & $4 \cdot 10^{-10}$ \\
\hline 3 & {$\left[\mathrm{Ni}\left(\mathrm{NH}_{3}\right)_{6}\right]^{2+}$} & октаэдрическая & $2 \cdot 10^{-9}$ \\
\hline
\end{tabular}






a



6

Рис. 5. Изотермы сорбции аммиака ионными формами волокна ВИОН КН-1 в координатах линейных уравнений Ленгмюра (а) и Фрейндлиха (б). Fig. 5. Isotherms of ammonia sorption by ionic forms of VION KN-1 fibre in the coordinates of the Langmuir (a) and Freundlich (b) linear equations.

центров модифицированного волокна. Участок, близкий к насыщению, характеризуется заполнением менее доступных активных центров, что требует более высоких давлений.

Медная форма поглощает наибольшее количество аммиака. Наименьшая сорбция характерна для водородной формы, что можно объяснить физической адсорбцией и образованием водородных связей молекул аммиака с карбоксильными группами полимерной матрицы волокна. Не модифицированное волокно обладает меньшей сорбционной способностью, что связано с различным механизмом сорбции молекул аммиака на протонированной и ионных формах волокна. Следует отметить, что при высоких давлениях значение сорбции близко к постоянному. В этом случае достигается полное насыщение сорбента и повышение давления уже не влияет на абсорбцию газа.

Сорбция аммиака в медной форме в 3.15 раза больше, чем на водородной, никелевой - 2.22 раза, цинковой - 2.03 раза, что согласуется с квантово-механиче скими расчетами в программном модуле Hyper Chem и основанными на них предположениями о повышении сорбционной способности модифицированных волокон в 2 раза [17].
Для количественного описания равновесного процесса сорбции аммиака ионными формами волокна были использованы уравнения Ленгмюра и Фрейндлиха. Между сорбцией и давлением отсутствует прямая зависимость, но она описывается эмпирическим уравнением Фрейндлиха:

$$
A=K \cdot P^{1 / n},
$$

где $A$ - величина адсорбции на единицу веса адсорбента, $P$ - равновесное давление газа, $K$ и $1 / n$ - константы адсорбции характерные для данного процесса адсорбции.

Изотерма сорбции линеаризуется только в обратных координатах уравнения Ленгмюра и не описывается в координатах уравнения Фрейндлиха (рис. 5), на что указывают и величины достоверности, представленные на рисунках. Коэффициенты корреляции для уравнения Ленгмюра близки к единице (рис. 5a).

Результаты расчетов предельного значения сорбции $\left(\mathrm{A}_{\infty}\right)$ и К (константы, соответствующей массе адсорбированного вещества при равновесной концентрации, равной единице) представлены в таблице4.

Уравнение Ленгмюра хорошо описывает адсорбцию, обусловленную силами, близкими по своей природе к химическим. Каждый активный центр адсорбирует молекулы адсорбата и на его поверхности образуется мономолекулярный 
Таблица 4. Константы изотерм сорбции по Ленгмюру

Table 4. Langmuir sorption isotherm constants

\begin{tabular}{|c|c|c|c|c|}
\hline № п/п & Солевая форма & $\mathrm{A}_{\infty}$, ммоль/Г & $\mathrm{K}$ & $\mathrm{R}^{2}$ \\
\hline 1 & Медная & 3.992 & 0.072 & 0.9996 \\
\hline 2 & Никелевая & 2.927 & 0.133 & 0.9983 \\
\hline 3 & Цинковая & 2.700 & 0.151 & 0.9990 \\
\hline 4 & Водородная & 1.402 & 1.137 & 0.9960 \\
\hline
\end{tabular}

слой. Адсорбированные молекулы аммиака удерживаются активными центрами в течение определенного времени, которое зависит от температуры. Силами взаимодействия между адсорбированными молекулами можно пренебречь.

Определение соотношения ионов металлов и сорбированного аммиака проводили для медной и никелевой форм. Концентрации ионов меди и никеля в растворах находили по градуировочному графику зависимости оптической плотности от молярной концентрации ионов, построенному по серии стандартных растворов. Содержание ионов металла для каждой из форм $\left(\left[\mathrm{Cu}^{2+}\right],\left[\mathrm{Ni}^{2+}\right]\right.$, ммоль/г сорбента) остается постоянным в пределах относительной погрешности: $4.7 \%$ для медной формы и 3.8 \% для никелевой формы волокна (табл. 5).

Содержание ионов меди (II) в модифицированном волокне почти в два раза выше, чем ионов никеля (II). Можно предположить, что катионы меди преимущественно образуют ионно-координационные центры типа I, а катионы никеля - типа II (рис. 6). В карбоксильных волокнах, насыщенных аммиаком, на 1 ион металла-комплексообразователя приходится 1.6 или 2.3 молекулы NH3. Данные таблицы подтверждают высказанное ранее предположение [17] об образова- нии на карбоксильном волокне, содержащем как медь, так и никель, комплексов, в состав которых входят от 1 до 3 молекул аммиака.

Для исследования кинетики сорбции аммиака были выбраны медная и никелевая формы модифицированных волокон, как самые эффективные. Применяли статистический метод, основанный на измерении концентрации ионов аммония в растворе после десорбции, в зависимости от времени.

Кинетические зависимости сорбции (рис. 7), полученные при концентрации аммиака в газовой фазе $10 \mathrm{Mr} / \mathrm{m}^{3}$, характеризуют скорость данного процесса.

При изучении кинетики сорбции и десорбции газов на поверхности твердых сорбентов применимы уравнения обратимых реакций первого порядка [18].

В общем случае для реакции первого порядка скорость (v) описывается уравнением:

$$
\vartheta=-\frac{d C}{d t}=k \cdot C
$$

где $C$ - концентрация исходного вещества [18].

Заменив концентрацию величиной сорбции и с учетом интегрирования получим:

$$
A=A_{p} \cdot\left(1-e^{-k \cdot \tau}\right)
$$<smiles>CC12OC(C)(O1)[C@](O)(CO)O2</smiles>

I<smiles>C[C@]12OC(O)(O)[C@H](O1)O2</smiles>

II

Рис. 6. Схемы образования ионно-координационных центров в волокне ВИОН КН-1

Fig. 6. Schemes of the formation of for ion-coordination centres in the VION KN-1 fibre 
Таблица 5.Соотношение концентраций ионов металла и аммиака

Table 5. The ratio of metal ions and ammonia concentrations

\begin{tabular}{|c|c|c|c|c|c|c|c|}
\hline $\begin{array}{l}\text { № } \\
\Pi / \Pi\end{array}$ & $\begin{array}{c}\text { Концен- } \\
\text { трация } \\
\text { NHз в га- } \\
\text { зовой } \\
\text { фазе, } \\
\text { мг/м }{ }^{3}\end{array}$ & $\begin{array}{c}\text { Концен- } \\
\text { трация } \\
\text { ионов } \\
\mathrm{Cu}^{2+}, \\
\text { ммоль/г } \\
\text { сорбента }\end{array}$ & $\begin{array}{c}\text { Сорбция ам- } \\
\text { миака на } \\
\text { медной } \\
\text { форме, } \\
\text { ммоль/г }\end{array}$ & $\begin{array}{c}\text { Соот- } \\
\text { ноше- } \\
\text { ние } \\
\text { кон- } \\
\text { цен- } \\
\text { траций } \\
{\left[\mathrm{NH}_{3}\right]:} \\
{\left[\mathrm{Cu}^{2+}\right]}\end{array}$ & $\begin{array}{c}\text { Концен- } \\
\text { трация } \\
\text { ионов } \\
\mathrm{Ni}^{2+}, \\
\text { ммоль/г } \\
\text { сорбента }\end{array}$ & $\begin{array}{c}\text { Сорбция ам- } \\
\text { миака на } \\
\text { никелевой } \\
\text { форме, } \\
\text { ммоль/г }\end{array}$ & $\begin{array}{c}\text { Соот- } \\
\text { ноше- } \\
\text { ние } \\
\text { концен- } \\
\text { траций } \\
{\left[\mathrm{NH}_{3}\right]:} \\
{\left[\mathrm{Ni}^{2+}\right]}\end{array}$ \\
\hline 1 & 10.00 & 2.301 & 2.282 & 0.992 & 1.268 & 1.408 & 1.110 \\
\hline 2 & $13, .62$ & 2.430 & 2.529 & 1.041 & 1.216 & 1.871 & 1.539 \\
\hline 3 & 15.70 & 2.378 & 2.746 & 1.155 & 1.141 & 2.088 & 1.830 \\
\hline 4 & 20.20 & 2.235 & 2.864 & 1.281 & 1.196 & 2.091 & 1.748 \\
\hline 5 & 35.93 & 2.547 & 3.261 & 1.280 & 1.288 & 2.591 & 2.012 \\
\hline 6 & 76.09 & 2.519 & 3.526 & 1.400 & 1.220 & 2.726 & 2.234 \\
\hline 7 & 139.17 & 2.340 & 3.808 & 1.627 & 1.261 & 2.847 & 2.258 \\
\hline 8 & 295.74 & 2.411 & 3.812 & 1.581 & 1.224 & 2.826 & 2.309 \\
\hline
\end{tabular}

Для нахождения константы скорости сорбции уравнение можно представить в виде:

$$
\ln \frac{A_{p}-A}{A_{p}}=k \cdot \tau
$$

где $\mathrm{A}$ - значение сорбции аммиака к моменту времени $\tau$, моль $/ \mathrm{M}^{3} ; A_{p}$ - равновесное значение сорбции аммиака, ммоль $/ \mathrm{m}^{3}$.

Экспериментальные данные, представленные в координатах этого уравнения (рис.8) дают прямую, по тангенсу



Рис. 7. Кинетические кривые сорбции аммиака на образцах медной и никелевой формы волокна ВИОН КН-1

Fig. 7. Kinetic curves of ammonia sorption on copper and nickel samples of VION KN-1 fibre угла наклона которой определяют численное значение константы скорости (табл. 6).

Для характеристики процесса сорбции пользуются величиной времени полупревращения $\left(\tau_{1 / 2}\right)$, равной промежутку времени, в течение которого сорбируется половина равновесного количества вещества [18]. Величина $\tau_{1 / 2}$ определяется для реакций первого порядка по формуле:

$$
\tau_{1 / 2}=\frac{\ln 2}{k}
$$

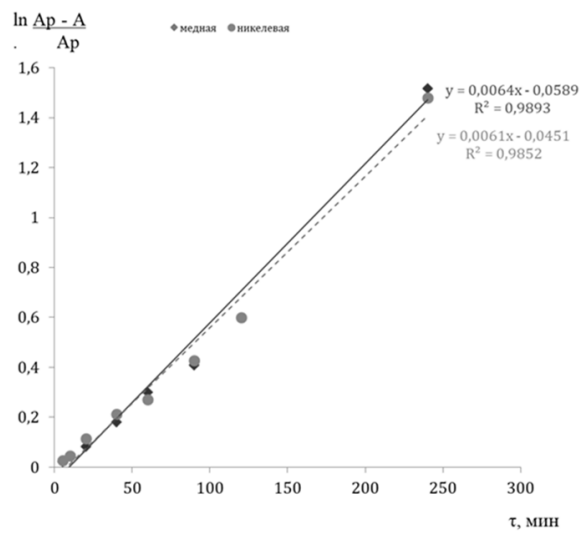

Рис. 8. Кинетические кривые сорбции аммиака на образцах медной и никелевой формы волокна, представленные

$$
\text { в координатах } \ln \frac{A_{R}-A}{A_{R}}-\tau
$$

Fig. 8. Kinetic curves of ammonia sorption on copper and nickel fibre, presented in coordinates $\ln \frac{A_{R}-A}{A_{R}}-\tau$ 
Таблица 6. Кинетические параметры сорбции аммиака

Table 6. Kinetic parameters of ammonia sorption

\begin{tabular}{|c|c|c|c|c|}
\hline № п/п & Солевая форма & $k$, мин $^{-1}$ & $\mathrm{R}^{2}$ & $\tau$, мин $^{-1}$ \\
\hline 1 & Медная & 0.00638 & 0.9893 & 114.5 \\
\hline 2 & Никелевая & 0.00605 & 0.9852 & 108.7 \\
\hline
\end{tabular}

Таблица 7. Сорбционные свойства воздушно-сухого и влагонасыщенного волокна ВИОН КН-1

Table 7. Sorption properties of air-dry and moisture-saturated VION KN-1 fibre

\begin{tabular}{|c|c|c|c|}
\hline \multirow{2}{*}{ Форма волокна } & \multicolumn{2}{|c|}{ Сорбция аммиака, ммоль/г } & $\begin{array}{c}\text { Понижение сорбци- } \\
\text { онной способности, } \\
\text { \% }\end{array}$ \\
\cline { 2 - 3 } & $\begin{array}{c}\text { Воздушно-сухое } \\
\text { волокно }\end{array}$ & $\begin{array}{c}\text { Влагонасыщеное } \\
\text { волокно }\end{array}$ & 10.4 \\
\hline Медная форма & 2.864 & 2.565 & 7.7 \\
\hline Никелевая форма & 2.091 & 1.930 & \\
\hline
\end{tabular}

Более высокой скоростью характеризуется медная форма модифицированного волокна. Скорость сорбции мала, что характерно для хемосорбции.

Для оценки влияния мешающих факторов, а именно водяных паров, сорбцию проводили для двух видов волокна - влагонасыщенного и воздушно-сухого при концентрации аммиака в газовой фазе 20 мг/м³ (ПДК рабочей зоны) (табл. 7).

Результаты показывают, что предварительное насыщение волокна влагой уменьшает сорбцию аммиака. Из данных по кинетически неравноценной воде в модифицированных волокнах (табл. 1) можно предположить, что молекулы воды, составляющие область средней гидратации оказывают наибольшее влияние на сорбцию аммиака. При контакте влагонасыщенного волокна с аммиаком происходит разрушение аквакомплексов с образованием более устойчивых аммиачных. При этом хемосорбционное волокно в медной форме удерживает сорбированную воду в большем количестве, чем в никелевой форме, что сказывается на суммарном содержании аммиака в волокне.

\section{Список литературы}

1.Горшунова В.П., Спиридонов Б.А., Федянин В.И. // Вестник Воронежского государственного технического университета. 2009. T. 5. № 12. C. 59-61.

\section{Заключение}

Показано, что модифицирование волокнистого карбоксильного ионообменника ионами $\mathrm{Cu}^{2+}, \mathrm{Ni}^{2+}, \mathrm{Zn}^{2+}$ увеличивает его сорбционную емкость. Полученные результаты позволили расположить модифицированные волокна в следующий ряд $\mathrm{R}-\mathrm{COOH}<\mathrm{R}-(\mathrm{COO})_{2} \mathrm{Zn}<\mathrm{R}-(\mathrm{COO})_{2} \mathrm{Ni}$ $<\mathrm{R}-(\mathrm{COO})_{2} \mathrm{Cu}$, в котором сорбционная способность возрастает.

Экспериментальные данные по сорбции были проверены с помощью изотерм Фрейндлиха и Ленгмюра. Результаты позволяют предположить, что для описания сорбции аммиака на модифицированных волокнистых сорбентах справедлива модель Ленгмюра. Определение соотношения ионов металлов и сорбированного аммиака для медной и никелевой формы показало, что на модифицированном карбоксильном волокне, образуются комплексы, содержащие от 1 до 3 молекул аммиака. По кинетическим кривым определено, что более высокой скоростью характеризуется медная форма волокна.

Предварительное насыщение модифицированных волокон парами воды ухудшает их сорбционные свойства на 8-10\%.

2. Воробьев А.Ю., Спиридонов Б.А., Горшунова В.П., Небольсин В.А. и др. // Вестник Воронежского государственного технического университета. 2012. Т. 8. № 7-2. С. 4-7. 
3. Горшунова В.П., Хаустова М.М. // Вестник ВГТУ. 2010. Т. 6. № 11. С. 19-21.

4. Горшунова В.П., Небольсин В.А., Лукин А.Н. // Современные проблемы науки и образования. 2012. № 3. С.424-432.

5.Vasiliev L.L., Kulakov A.G., Mishkinis D.A., Safonova A.M. et al. // «Activated Carbon For Gas Adsorption», in 3d Int. Symposium on Fullerene and Semifullerene Structures in the Condensed Media. Minsk. Belarus. 22-25 June. 2004. pp. 110-115.

6. Vasiliev L.L., Kanonchik L.E., Kulakov A.G., Mishkinis D.A. et al. // International Journal of Low Carbon Technologies. 2006. Vol. 1(2), pp. 95-111.

7. Ксандров Н.В., Ожогина О.Р. // Известия вузов. Химия и химическая технология. 2018. T. 61. № 8. C. 53-58. https://doi.org/10.6060/ ivkkt201861008.5726

8. Sharonov V.E., Veselovskaya J.V., AristovYu.I. // Int. J. Low Carbon Tech. 2006. Vol. 1. No 3. pp. 191-200.https://doi.org/10.1093/ ijlct/1.3.191

9. Аристов Ю.И., Гордеева Л.Г. // Кинетика u катализ. 2009. Т. 50. № 1. С. 72-79. https://doi.org/10.1134/S0023158409010091

10. Veselovskaya J.V., Tokarev M.M., Aristov Yu.I. // Appl. Therm. Eng. 2010. Vol. 30. No 6-
7. pp. 715-723. https://doi.org/1 0.1016/j.applthermaleng.2009.11.001

11. Tokarev M.M., Veselovskaya J.V., Yanagi H., Aristov Yu.I. // Appl. Therm. Eng. 2010. Vol. 30. No 8-9/ pp. 845-849. https://doi.org/ 10.1016/j.aplthermaleng.2009.12.016

12. Поликарпов А.П., Шункевич А.А., Грачек В.И., Медяк Г.В. // Российский Химический журнал. 2015. Т. 59. № 3.С. 102-111.

13. Косандрович Е.Г., Дорошкевич О.Н. // Весцінацыя нальнойа кадэми навук Беларусі. 2014. № 1. C.91-95.

14. Astapov A.V., Peregudov Y.S., Popova K.A., Kopylova V.D // Russian Journal of Physical Chemistry A. 2010. Vol. 84. No 3. pp. 491-494.

15. Лидин Р.А, Андреева Л.Л., Молочко В.А. Константы неорганических веществ: справочник. М. Дрофа. 2006. 685 с.

16. Соколовский А.Е., Радион Е.В. Физикохимические методы анализа. Минск. БГТУ. 2007. $118 \mathrm{c}$.

17. Нифталиев С.И., Астапов А. В., Перегудов Ю.С, Бакаева Ю.В. // Конденсированные среды и межфразные границь. 2012. Т. 14. № 2. C. 221-223.

18. Романовский Б.В. Основы химической кинетики. М. Экзамен. 2006. 415 с.

\title{
Investigation of the sorption of ammonia from a gas-air medium bymodified ion exchange fibres
}

\author{
(C) 2021 Peregudov Yu.S., Plotnikova S.E., Gorbunova E.M., Timkova A.V., \\ Kim K.B., Niftaliev S.I.
}

Voronezh State University of Engineering Technologies, Voronezh

\begin{abstract}
Purification of process gases from ammonia is an urgent problem in the chemical industry. The aim of the research was investigation of the sorption of ammonia from a gas-air medium by modified fibrous sorbents. Carboxyl fibre VION KN-1 in copper, nickel and zinc forms was used as an ammonia sorbent. The study of the absorption of ammonia was carried out on air-dry and moisture-saturated samples of the fibrous sorbent. For the study of sorption in desiccators, atmospheres with a volume concentration of ammonia from 10 to $300 \mathrm{mg} / \mathrm{m}^{3}$ were created. The maximum permissible concentration of ammonia in the air of the working area was $20 \mathrm{mg} / \mathrm{m}^{3}$. After sorption of ammonia, the modified fibrous sorbents acquired colours characteristic of amino complexes. The fibre with absorbed ammonia was treated with a solution of hydrochloric acid with a concentration of $0.1 \mathrm{~mol} / \mathrm{dm}^{3}$ under static conditions at a temperature of $293 \mathrm{~K}$ for 90 minutes. The concentration of ammonium ions was determined using I-130 ion meter with an ion-selective electrode. The photometric method was used to determine the concentration of metal ions in solutions after desorption. It was established that the copper form absorbs the greatest amount of ammonia. At low gas pressures, a sharp absorption of ammonia by the modified fibre was observed. Unmodified fibre has a lower sorption capacity, which was explained by the different mechanism of sorption of ammonia molecules on the protonated and ionic forms of the fibrous sorbent. The Langmuir and Freundlich equations were used for quantitatively description of the equilibrium process of ammonia sorption by modified fibres. The correlation coefficients for the Langmuir equation were close to one. At high pressures, the sorbent was completely saturated and the increase in pressure no longer affected the gas absorption. The obtained results on the sorption of ammonia are
\end{abstract}


consistent with quantum-mechanical calculations in the Hyper Chem software module on the formation of complexes containing from 1 to 3 ammonia molecules on a carboxyl fibre containing both copper and nickel. Kinetic dependences of ammonia sorption on samples of copper and nickel forms of VION KN-1 fibre were obtained with an ammonia concentration in the gas phase of $10 \mathrm{mg} / \mathrm{m}^{3}$.

It has been shown that the copper form of the fibre sorbent is characterized by a higher sorption rate. Saturation of modified carboxylic fibres with water vapour impaired their sorption properties by $8-10 \%$.

Keywords: sorption, ammonia complexes, modified carboxylic fibres

\section{References}

1. Gorshunova V.P., Spiridonov B.A., Fedjanin V.I., Proceedings of the Voronezh State University of Engineering Technologies, 2009, Vol. 5, No 12, pp. 59-61.

2. Vorob'evA.Ju., Spiridonov B.A., Gorshunova V.P., Nebol'sin V.A. et al., Proceedings of the Voronezh State University of Engineering Technologies, 2012, Vol. 8, No 7-2, pp. 4-7.

3. Gorshunova V.P., Haustova M.M., Vestnik VSTU, 2010, Vol. 6, No 11, pp. 19-21.

4. Gorshunova V.P., Nebol'sin V.A., Lukin A.N., Modern problems of science and education, 2012, No 3, pp. 424-432.

5. Vasiliev L.L., Kulakov A.G., Mishkinis D.A., Safonova A.M. et al. «Activated Carbon For Gas Adsorption», in 3d Int. Symposium on Fullerene and Semifullerene Structures in the Condensed Media, 22-25 June, Minsk, Belarus, 2004, pp. 110-115.

6. Vasiliev L.L., Kanonchik L.E., Kulakov A.G., Mishkinis D.A. et al., International Journal of Low Carbon Technologies, 2006, Vol. 1(2), pp. 95-111.

7. Ksandrov N.V., Ozhogina O.R., Izvestija vuzov. Himija i himicheskaja tehnologija, 2018, Vol. 61, No 8, https://doi.org/10.6060/ ivkkt201861008.5726

8. Sharonov V.E., Veselovskaya J.V., AristovYu.I., Int. J. Low Carbon Tech., 2006, Vol. L, No 3, pp. 191-200.https://doi.org/ 10.1093/ijlct/1.3.191

Перегудов Юрий Семенович - к.Х.н., доцент кафедры неорганической химии и химической технологии, Воронежский государственный университет инженерных технологий, Воронеж

Плотникова Светлана Егоровна - к.Х.Н., доцент кафедры неорганической химии и химиче-
9. Aristov Ju.I., Gordeeva L.G., Kinetika I kataliz, 2009, Vol. 50, No 1, pp. 72-79. https://doi.org/10.1134/S0023158409010091

10. Veselovskaya J.V., Tokarev M.M., Aristov Yu.I., Appl. Therm. Eng., 2010, Vol. 30, No 6-7, pp. 715-723. https://doi.org/10.1016/j.aplthermaleng.2009.11.001

11. Tokarev M.M., Veselovskaya J.V., Yanagi H., Aristov Yu.I., Appl. Therm. Eng., 2010, Vol. 30, No 8-9, pp. 845-849. https://doi.org/10.1016/ j.applthermaleng.2009.12.016

12. Polikarpov A.P., Shunkevich A.A., Grachek V.I., Medjak G.V., Russian Chemical Journal, 2015, Vol. 59, No 3, pp. 102-111.

13. Kosandrovich E.G., Doroshkevich O.N., Bulletin of the National Academy of Sciences of Belarus, 2014, No 1, pp. 91-95.

14. Astapov A.V., Peregudov Y.S., Popova K.A., Kopylova V.D., Russian Journal of Physical Chemistry A, 2010, Vol. 84, No 3, pp. 491494.

15. Lidin R.A, Andreeva L.L., Molochko V.A. Konstanty neorganicheskih veshhestv: spravochnik, M., Drofa, 2006, 685 p.

16. Sokolovskij A.E., Radion E.V. Fizikohimicheskiemetodyanaliza, Minsk, BGTU, 2007, 118 p.

17. Niftaliev S.I., Astapov A.V., Peregudov Ju.S, Bakaeva Ju.V., Kondensirovannye sredy $i$ mezhfaznye granicy, 2012, Vol. 14, No 2, pp. 221-223.

18. Romanovskij B.V. Osnovy himicheskoj kinetiki. M., Jekzamen, 2006, 415 pp.

Peregudov Yuri S. - Ph.D in Chemistry, associate professor at the Inorganic Chemistry and Chemistry Technology, Voronezh State University of Engineering Technology, Voronezh, Russian Federation; e-mail: inorganic 033@mail.ru

Plotnikova Svetlana E. - Ph.D in Chemistry, associate professor at the Inorganic Chemistry and Chemistry Technology, Voronezh State University 
ской технологии, Воронежский государственный университет инженерных технологий, Воронеж

Горбунова Елена Михайловна - к.Х.н., доцент кафедры неорганической химии и химической технологии, Воронежский государственный университет инженерных технологий, Воронеж

Тимкова Анна Васильевна - аспирант кафедры неорганической химии и химической технологии, Воронежский государственный университет инженерных технологий, Воронеж

Ким Ксения Борисовна - к.Х.н., доцент кафедры неорганической химии и химической технологии, Воронежский государственный университет инженерных технологий, Воронеж

Нифталиев Сабухи Илич оглы - д.х.н., профессор кафедры неорганической химии и химической технологии, Воронежский государственный университет инженерных технологий, Воронеж of Engineering Technology, Voronezh, Russian Federation; e-mail: burkovasweta@yandex.ru.

Gorbunova Elena M. - Ph.D in Chemistry, associate professor at the Inorganic Chemistry and Chemistry Technology, Voronezh State University of Engineering Technology, Voronezh, Russian Federation; e-mail:lobanova8686@gmail.com

Timkova Anna V. - post-graduate student at the Inorganic Chemistry and Chemistry Technology, Voronezh State University of Engineering Technology, Voronezh, Russian Federation; e-mail: timkova.anna@mail.ru

Kim Kseniya B. - Ph.D in Chemistry, associate professor at the Inorganic Chemistry and Chemistry Technology, Voronezh State University of Engineering Technology, Voronezh, Russian Federation; e-mail:kmkseniya@yandex.ru

Niftaliev Sabukhi Ilich ogli - DSc in Chemistry, Professor at the Inorganic Chemistry and Chemistry Technology, Voronezh State University of Engineering Technology, Voronezh, Russian Federation; e-mail:sabukhi@gmail.com. 